\title{
A percepção da morte por idosos institucionalizados: estudo fenomenológico em dois lares residenciais portugueses
}

\author{
Death perception by institutionalized elderly people: Phenomenological Study in two \\ residential homes
}

\section{Ernesto Candeias Martins*}

\begin{abstract}
Resumo:
A ideia de morte e perdas da perspectiva de idosos institucionalizados implicam questões quanto à finalidade da vida. A seguinte pesquisa aborda a percepção quanto à morte e à morte do outro em idosos de 2 lares residenciais $(N=35)$. De metodologia mista (predominância qualitativa) e teor exploratório (analítico, descritivo e interpretativa), transversal e fenomenológico, inserida no Projeto Gerontológico do mestrado, os dados coletados baseiam-se na Escala Breve Perspectivas da Morte, Escala Geriátrica de Depressão de Yesavage; entrevistas semiestruturadas aos idosos; observação participante; notas campo. Utilizamos como tratamento de dados a triangulação. Resultados confirmam que as perspectivas da morte e morte do outro têm relação com o sentido de vida do idoso, ambiente institucional e vivências (medo, dor, sofrimento, isolamento), podendo desencadear em alguns deles sentimentos negativos/depressivos.
\end{abstract}

Palavras-chave: Idoso institucionalizado. M orte. Perdas. Representação. Depressão.

\begin{abstract}
:
The idea of death and loss perspective by institutionalized elderly involve questions about life purpose. The following research addresses the perception of death and the death of another in 2 elderly residential homes $(\mathrm{N}=35)$. Using of mixed methodology (qualitative predominance) exploratory content (analytical, descriptive and interpretive), transversal and phenomenological, inserted in the Gerontology master project, the collected data uses the Short-Range Perspectives of Death, Yesavage Geriatric Depression Scale; elderly structured interviews; participants observation and field notes. Triangulation method was used to treat the data. Results confirm that the perspectives of death and another's death have to do with the meaning of life believed by the elderly, institutional environment and previous experiences (fear, pain, suffering, isolation), and can trigger negative and depressive feelings on some of them.
\end{abstract}

Keywords: Elderly institutionalized. Death. Losses. Representation. Depression.

\footnotetext{
* Doutor e mestre em Ciências da Educação, respectivamente pela Universidade Illes Balears (Palma de Mallorca -Espanha) e na Universidade Católica Portuguesa. licenciado em Filosofia pela Universidade Católica Portuguesa e em Pedagogia/Ciencias da Educação pela Universidade Pontíficia de Salamanca / Universidade de Lisboa - FPCE, docente no Instituto Politécnico de Castelo Branco/Escola Superior de Educação, (co) coordenador dos M estrados em Educação do 1.ำ Ciclo, do 1.ㅇ / 2.. Ciclo, Intervenção Social Escolar e Educação Especial e do Curso de Licenciatura em Educação Básica na mesma instituição. Membro do centro de investigação - CeiEF da Universi dade Lusófona de Lisboa
} 


\section{Questões introdutórias}

É sabido que o processo de envelhecimento envolve ganhos e perdas que provocam alterações em diferentes níveis sociais e fisiológicos. Dentre as perdas está a morte do outro (cônjugue, familiar, vizinho, amigo, etc.) (KóVACS, 2010), que induz a percepção e conscientização do que é a morte e leva a reações como dor, sofrimento, sentimentos de ansiedade, inquietação, desânimo, cessação de interesses, inibição de realizar certas atividades, luto, etc.

A percepção da morte pelo idoso em instituições de longa permanência ou lar residencial é influenciada por padrões sociais, culturais, religiosos e vivências, pois trata-se de uma representação do ser humano na sua adaptação ao meio ambiente e à influência deste. Daí ser pertinente compreender a perspectiva de perda e morte para os idosos residentes, sabendo que é uma realidade complexa e um problema real, já que "[...] qualquer tentativa de bloquear ou negar os sentimentos, tal como a incompreensão dos mesmos, acaba por refletir-se na saúde física e mental, gerando vários problemas." (OLIVEIRA, 2011, p. 24).

$\mathrm{Na}$ busca de teorias, a literatura evidencia a pertinência do acompanhamento ao idoso institucionalizado após perdas, levando em conta sua idade, condição de vulnerabilidade e ainda o apoio dos cuidadores, familiares ou voluntários. Sendo uma necessidade para muitos idosos, a institucionalização é, simultaneamente, um fator desencadeador de novos (re)ajustes internos para o indivíduo, estimulo de novas interações sociais e a criação de laços com aqueles ao seu redor. Estas interações, de acordo com as afinidades desenvolvidas, propiciam o desenvolvimento de reações e (des)ajustes após a(s) perda(s).

A morte do outro é uma percepção feita pelo idoso sobre alguém próximo, seja familiar ou não, seja a pessoa que coabita com ele, que fazia ou que passou a fazer parte da sua vida e com quem partilha experiências no contexto institucional (SOARES et al., 2009). Nossa pesquisa, inserida na área da Gerontologia Social e realizada em 2016, ancora-se na metodologia mista (preponderância qualitativa no design), tendo como problema a percepção sobre a morte, a morte do 'outro', as perdas e respectivas implicações na vida cotidiana de idosos em lar residencial. 
o estudo assumiu um caráter analítico, descritivo e exploratório ao buscar aprofundar a realidade dos idosos institucionalizados. Os objetivos subjacentes são os seguintes: Descrever o perfil sociodemográfico dos idosos residentes em 2 lares portugueses e dos respectivos técnicos/responsáveis; Compreender se as perdas mais significativas para o idoso, antes da sua institucionalização, influenciam essa aceitação da perda do outro posteriormente na institucionalização; Analisar as representações no que concerne ao significado da morte e da morte do outro; Compreender se as perceções atribuídas pelo idoso diferem de acordo com gênero, idade, escolaridade, religião, tempo de institucionalização e níveis de depressão; Comparar os dados das Escalas Breves Sobre às Diversas Perspectivas da M orte com a Escala Geriátrica de Depressão nos 2 lares; Analisar se os idosos sentem necessidade de receber apoio após a perda do outro; Determinar 0 apoio institucional fornecido aos idosos após a perda do outro e implicações na sua vida quotidiana.

A amostra compôs-se de 35 idosos residentes em 2 lares residenciais portugueses na cidade de Castelo Branco, um pertencente à rede das misericórdias e o outro a uma entidade privada. Usou-se como técnicas de recolhimento de dados: entrevistas estruturadas aos idosos e Escalas Breves Sobre Diversas Perspectivas da Morte de Spilca e col., traduzida e aferida por Barros-Oliveira e Neto (2004) e a Escala Geriátrica de Depressão (YESAVAGE et al., 1983); observação dos participante; notas de campo.

Os resultados obtidos provenientes do método da triangulação confirmaram que às perspectivas da morte e morte do outro relacionam-se com o sentido de vida do idoso, ambiente institucional, perceções psicossociais e vivências, as quais desencadeiam sentimentos negativos ou situações depressivas (GUERRA; CALDAS, 2010).

A morte para o idoso institucionalizado é vista e representada como um momento de sofrimento, dor, agonia, medo e isolamento, de abandono de quem ama e como finitude (FRUMI; CELICH, 2006). Todavia são as mulheres que demonstram mais o sofrimento/dor quando comparadas aos homens, evidenciando crenças ou representações que existe vida para além da morte, devido à incidência da religiosidade e crenças (M ORIN, 1970). 


\section{Fundamentos teórico-concetuais}

Mesmo havendo melhoria na qualidade de vida e aumento da esperança de vida, existe um elevado envelhecimento da população com os avanços de determinadas ciências biológicas e médicas e controlo de doenças, que fazem da morte um acontecimento cada vez mais longínquo. Esse envelhecimento demográfico desenvolve paralelamente alterações sociais que afetam a vida dos idosos, como a globalização das economias; a maior propensão a viver-se em cidades; a evolução tecnológica rápida; às alterações demográficas e nas famílias - o que significa menos familiares para cuidarem dos seus idosos; à propensão a terse menos filhos, não ser casado e não propensão a viver com a geração mais velha, etc. (CABRAL et al., 2013).

Estudos científicos sobre o envelhecimento têm fornecido muitos dados que permitem observar o desenvolvimento de várias teorias interdisciplinares explicativas desse processo, mencionamos (BENGSTON et al., 2009; M ARTINS, 2013): teorias biológicas (teorias biológicas da senescência; teorias do stress); teorias psicológicas (teoria da seleção, teorias da cognição; teorias da competência no quotidiano); teorias sociológicas.

0 envelhecimento constitui uma perda progressiva de capacidades de adaptação do organismo às condições variáveis do ambiente, de modo a poder efetuar às tarefas de vida diária. 0 quadro teórico-concetual deste estudo assentou em três âmbitos de fundamentação: o processo de envelhecimento, a institucionalização do idoso e sua concepção da morte e perda.

Envelhecer o mais ativo possível

A longevidade aumentada do indivíduo na sociedade revela-se profundamente desafiante, o que leva a uma nova mutualidade de relação sociedade/sujeito. Gerontologicamente a temática velhice e envelhecimento têm despertado cada vez mais o interesse dos estudiosos e sociedade. Isto deve-se ao precoce aumento do envelhecimento global originado pela redução da taxa de natalidade e pelo aumento da esperança média de vida, proporcionada por inúmeros avanços tecnológicos em diversos campos científicos (NETTO, 2002).

0 processo de envelhecimento e às alterações sociais descritas levantam questões quanto a necessidade de ajuste das sociedades a fim de melhorar os meios de apoio às 
pessoas idosas, garantindo o bem-estar. Assim, é crucial estabelecer estratégias promotoras de um envelhecimento autónomo e saudável ainda favorecendo a qualidade de vida dos idosos mediante às alterações sociais, com os apoios/cuidados necessários, sobretudo quando a família já não tem capacidade de assegurar à sua segurança e assistência (GALLHA, 2013).

Visto de diversas formas (teorias) dependendo das diferentes culturas há diversidade nas formas de envelhecer. Envelhecimento e velhice deixaram de ser encarados como naturais para serem um fenômeno profundamente influenciado pela cultura. Nesse contexto, torna-se necessário conhecer e compreender à percepção e significados atribuídos pelo idoso quanto ao seu envelhecimento e, ainda como o integra nas suas experiências cotidianas. Esta percepção tende a quantificar-se de maneira íntegra e real nas mudanças percebidas no ambiente social e no próprio corpo (físico, mental) (GUERRA; CALDAS, 2010).

Ninguém mais que o próprio idoso vivencia esse fenômeno, dando-lhe indícios de compreensão do que é ser idoso, o que é envelhecer, ser (in)dependente. É essencial lidar com 0 envelhecimento, a velhice e com as principais fontes de angústia que o ser humano idoso experimenta e respeitar sua individualidade, autonomia e singularidade como ser - daí a necessidade de apoios e serviços adequados (KÜBLER-ROSS, 2005).

Nem todos os seres humanos envelhecem do mesmo modo e a mesma velocidade. Moragas (1997) indica três concepções sobre a velhice: a cronológica, que é caraterizada pela idade de 65 anos quando se dá a aposentadoria, em que as pessoas são agrupadas em anos; a funcional, que corresponde ao uso do termo 'velho' como sinônimo de incapaz ou limitado devido às reduções na sua capacidade funcional próprias do processo de envelhecimento; a etapa final, sendo a concepção mais equilibrada e moderna, que se baseia no reconhecimento de que há um processo de envelhecimento produzido nas pessoas.

Esse processo é caraterizado por certas limitações que vão se agravando nos últimos anos de vida (LIM A; MURAI, 2005). Assim, a velhice é um processo pessoal, natural, indiscutível e inevitável para qualquer ser humano na evolução da vida, havendo duas formas básicas em que ocorrerem mudanças: de maneira consciente e tranquila, reconhecendo o que há de importante nessa etapa de vida para desfrutá-la da melhor maneira, mesmo com limitações, surgindo imagens bem mais positivas da velhice e do envelhecimento; ou então com grande intensidade quando associada à doença e 
incapacidade, caso onde os idosos tendem a representar imagens negativas da velhice (CABRAL et al., 2013).

Processo de institucionalização dos idosos

As mudanças políticas, em Portugal, implementaram a ação social, que agrupa um conjunto de ações desenvolvidas, através de serviços e equipamentos sociais de apoio individual e familiar, além da intervenção comunitária. Estas ações têm como objetivo estruturar, explícita ou implicitamente, as relações entre a velhice e a sociedade, implicando que os encargos com idosos, que anteriormente eram da responsabilidade da família ou de particulares, fossem delegados a instâncias despersonalizadas e burocratizadas.

Quando o idoso não encontra respostas às suas necessidades no seu meio social, a institucionalização torna-se uma opção para a manutenção da sua qualidade de vida. Atualmente existem equipamentos de índole social que buscam colmatar às necessidades dos idosos, tendo o papel de cuidar daqueles que envelhecem. Entretanto a institucionalização também levanta questões relativas à adaptação e qualidade de vida dos idosos, sabendo que o Manual de Boas Práticas da Segurança Social refere que "[...] quem vive em acolhimento residencial deve sentir-se em sua casa." (ISS, 2005, p. 12).

A redefinição da institucionalização busca favorecer às relações interpessoais saudáveis e o significado das trajetórias na busca da dignidade no envelhecimento. Assim, a ação social exerce-se maioritariamente por Instituições Particulares de Solidariedade Social (IPSS) e outras organizações privadas (misericórdias e rede privada) apoiadas pelo Estado, consignadas no Decreto-Lei $n$ ํ 119/83, de 25 de fevereiro, que alargou o conceito de IPSS, com revisão do estatuto aplicado em 1979.

As IPSSs têm por finalidade a prevenção e o apoio nas diversas situações de fragilidade, exclusão ou carência humana, promovendo a inclusão/integração social, desenvolvendo diversas atividades às populações necessitadas. As áreas destinadas ao processo de envelhecimento avançaram significativamente, surgindo equipamentos ou valências para às pessoas idosas que favoreceram à expansão do conhecimento sobre os idosos (BENGSTON et al., 2009), divididas em: apoio domiciliar (Dec. Lei n. 99/2011, de 28/09); centro de convívio; centro de dia (Dec. Lei n.9 99/2011, de 28/09); centro de noite 
(Portaria no 96/2013 de 4/03); acolhimento familiar e estrutura residencial (Portaria no 67/2012, de 21/03).

A institucionalização representa uma grande mudança na vida do idoso, acentuando a convivência com constantes perdas como sua vida social e interferindo em sua independência, individualidade, privacidade e outros fatores que podem representar sua exclusão social na medida em que se afasta de suas relações sociais. Ao entrar na instituição o idoso começa a partilhar espaços com pessoas desconhecidas, com quem poderá ou não desenvolver laços sociais afetivos.

"A realidade da sua finitude, é agora, no espaço e no tempo institucional, que se voltará para os fantasmas de morte, sentidos como cada vez mais próximos." (CARDÃO, 2009, p. 13). Há uma mudança cultural gradativa com dificuldades em acompanhar o mundo exterior e uma perca de alguns papéis, devido à barreira que o separa do mundo exterior. Esse processo depende muito das diferentes caraterísticas e perfil do idoso, que se apresenta cada vez mais ativo, dinâmico e interativo, sabendo que maioritariamente apresenta algumas limitações ou dependências. Daí a exigência por parte dos idosos de novos modos/maneiras de satisfação das suas necessidades durante a institucionalização.

Da Sociologia da morte à construção de uma 'morte humanizada'

O tema da morte sendo um tabu social, é muitas vezes negado, devido às atuais caraterísticas sociais da sua não-aceitação, da mistificação da juventude eterna, não havendo espaço para o morrer (THOM AS, 1991). Sabemos que morremos (finitude da vida) e por isso a morte aflige o ser humano, pois é um acontecimento que atinge não apenas quem morre, mas toda a estrutura familiar e social de quem falece (BARBOSA, 2003).

No final do século passado instituiu-se uma nova maneira de gerir o final da vida surgindo o direito de morrer com "dignidade", onde a boa morte é aquela morte consciente, sendo a dimensão psicológica fundamental. Essa legitimidade determinou voltar a "humanização" da morte, sabendo que há questões sobre doenças propiciarem à presença de dor, sofrimento e o então falecimento. O significado das perdas na velhice define-se como um fenômeno associado à morte, que desencadeia sensações, reações e estados de ânimo negativos que necessitam de apoio institucional, familiar e social. 
Há questões que se apresentam aos idosos com a proximidade da morte como: 0 sentido da vida, doenças, sofrimento, o que que resta para ser vivido, desprendimento da família, etc (CLAVANDIER, 2009). São essas e outras angústias expressas pelos idosos que vão se registando na vida cotidiana de um lar residencial. A falta de preparação por parte do idoso e dos profissionais gerontólogos que o acompanham, peca em proporcionar-Ihe 0 autêntico cuidado e apoio em questões que com o aproximar da morte, como às doenças, a dependência de outro, o sofrimento, a solidão e etc, que estão para além das necessidades meramente biológicas (PUIGDENGOLAS, 2003),

Por outro lado a depressão é a principal causa de incapacidade em todo o mundo, sendo que a geriátrica é associada a um maior declínio na saúde devido a várias doenças (crônicas, diabetes, demências) e por isso não só provoca sofrimento, dor, destabilização, aumento da comorbidade médica e incapacidade e, mas também implica risco de suicídio. Alguns estudos mostram um declínio na prevalência de depressão nos idosos em comparação com adultos de meia-idade, verificando prevalência de $12-14 \%$ de idosos institucionalizados diagnosticados com e uma porcentagem maior experimenta síndromes depressivas menos graves (VERÍSSIM O, 1988).

\section{Metodologia da pesquisa}

Seguimos a metodologia mista com preponderância qualitativa, pois os métodos qualitativos dão ênfase às especificidades de um determinado fenômeno, como é o caso da morte e morte do outro com consequências no estado de vida e de espírito dos idosos, devido ao sentido de perdas, luto, sofrimento, etc. Daí utilizamos o método fenomenológicoqualitativo de análise interativa e interpretativa da morte.

Estabelecemos as seguintes questões de investigação:

Que. 1 - Significado da 'morte' e da 'morte do outro' nos idosos institucionalizados (entrevistas, observação participante/notas de campo).

Que. 2 - Se as perdas mais significativas antes da institucionalização do idoso influenciam sua aceitação da perda do outro durante a institucionalização atual nos lares residenciais (entrevistas, observação participante/notas de campo).

Que. 3 - Se os significados das representações atribuídos pelo idoso institucionalizado quanto à 'morte' e à 'morte do outro' diferem de acordo com as variáveis 
gênero, idade, escolaridade, religião, tempo de institucionalização e níveis de depressão (dados das Escalas, entrevistas e notas de campo).

Que. 4 - Verificar as diversas perspectivas dos idosos institucionalizados sobre a 'morte' mensuradas pelas pontuações nas Escalas Breves Sobre Diversas Perspectivas da Morte.

Que. 5 - Qual a correlação existente entre as Escalas Breves Sobre Diversas Perspectivas da Morte e a Escala Geriátrica de Depressão -GDS-30.

Que. 6 -Se os idosos institucionalizados sentem necessidade de receber apoio após a perda do outro dado pela instituição (entrevistas e notas de campo).

A amostra foi selecionada por conveniência (FORTIN, 1999) (critérios assente na experiência e/ou vivência da perda do outro no período de institucionalização e em adequadas condições mentais) sendo composta por $\mathrm{N} 1=35$ idosos institucionalizados de 2 Lares residenciais (SCM e LR) em Castelo Branco. Cumprimos todas as normas legais e éticas estabelecendo contatos iniciais informais, protocolo (institucionais) e termo de livre consentimento dos idosos. A recolha de dados realizou-se de janeiro a abril de 2016, respeitando os horários preestabelecidos das instituições.

$57,1 \%$ da amostra era do sexo feminino, idade entre 81 e 90 anos $(68,6 \%)$, de religião católica $(97,1 \%)$, viúvos (80\%), baixas habilitações literárias $(88,5 \%)$, donas de casa (40\%), com tempo médio de institucionalização de 3,7 anos. Idosos referiram que a institucionalização provoca problemas de saúde (60 \%), de solidão ou estar sozinho $(22,9 \%)$, mas encontrando-se satisfeitos $(42,9 \%)$ ou muito satisfeitos $(37,1 \%)$ com a instituição $(42,9 \%)$, onde suas relações com os outros pares é 'satisfatória' $(62,9 \%)$ ou muito satisfatória $(31,4 \%)$.

Técnicas e instrumentos de medida

Aplicamos a técnica de entrevista semiestruturada, Escala Breve Sobre Diversas Perspectivas da Morte e a Escala Geriátrica de Depressão, além dos registos de observação natural, participante e notas de campo (BOGDAN; BIKLEN, 1994, p. 150). As Escalas Breve Sobre Diversas Perspectivas da Morte (BARROS-OLIVEIRA; NETO, 2004) apresentam um formato Likert de 6 intervalos em que os resultados variam entre 43 à 258 pontos, sendo composta por 8 escalas: Escala 1 "morte como sofrimento e solidão" (SS), com 6 itens e 
pontuação máxima 36; Escala 2 "morte como além-vida de recompensa" (VA), com 6 itens e pontuação máxima 36; Escala 3 "indiferença perante a morte" (MI), com 4 itens e pontuação máxima 30; Escala 4 "morte como desconhecido" (MD), com 6 itens e pontuação máxima 36; Escala 5 "morte como abandono dos que dependem de nós com a consequente culpabilidade" (MA), com 5 itens e pontuação máxima 30; Escala 6 "morte como coragem" (MC), com 6 itens e pontuação máxima 36; Escala 7 "morte como fracasso" (MF), com 5 itens e pontuação máxima 30; Escala 8 "morte como fim natural" (MN), com 4 itens e pontuação máxima 24.

Os dados psicométricos das escalas apresentam valores dos coeficientes de consistência interna Alfa de Cronbach elevados para amostras heterógenas, variando entre 0.78 Escala 8 e 0.94 para a Escala 2. Ao correlacionarmos às 8 subescalas entre si observamos correlações significativas, destacando-se a forte correlação de $p=0.54$ entre a Escala 2 e a Escala 6.

Em relação à Escala Geriátrica de Depressão (GDS-30) de Yesavage et al. (1983) que foi traduzida, aferida e adaptada à população portuguesa por Teixeira Veríssimo (1988), na "Avaliação Diagnostica das Síndromes Demenciais" no serviço de Neurologia e Neurocirurgia no Hospital S. João no Porto, a escala é composta por 30 itens em escala nominal (Sim/Não), sendo um instrumento de diagnóstico que permite detectar se há sintomas depressivos nos idosos institucionalizados. Embora não fosse o nosso intuito verificar as causas dos sinais de depressão e/ou proceder ao seu diagnóstico, quisemos associar a depressão caso houvesse correlação com a perspectiva do idoso sobre a morte e morte do outro.

Há 11 itens de resposta nominal SIM a pontuarem negativamente (zero) e 19 com resposta NÃO a pontuarem com um ponto. A classificação dos resultados são: entre 0 à 10 pontos "ausência de depressão"; entre 11 à 20 pontos a presença de "depressão ligeira" e entre 21 à 30 "depressão grave" (DRAGO; MARTINS, 2012). No tratamento dos dados (scores, pontuações) aplicou-se a correlação de Pearson às questões formuladas. Relativamente à suas propriedades psicométricas, a GDS-30 tem boas medidas de consistência interna $(a$ lfa $=0,94)$ e de confiabilidade $(0,94)$, de igual modo sugere estabilidade no Re-teste de 8 dias $(r=0,85)$. 


\section{Análise e tratamento dos dados: triangulação}

No tratamento dos dados aplicamos a triangulação (FLICK, 2005). A combinação de métodos quantitativos e qualitativos (design misto) permitiu que a triangulação dos dados estabeleça interdisciplinaridade à multiplicidade de informações provenientes das Escalas Breves Sobre Diversas Perspectivas da M orte, Escala Geriátrica de Depressão, da observação participante/notas de campo e entrevistas. Nas entrevistas aplicou-se a análise de conteúdo por meio de um mecanismo de dedução com base em indicadores reconstruídos a partir de uma amostra de mensagens particulares (BARDIN, 2009, p. 46). Basicamente 0 intuito da análise de conteúdo é favorecer à produção máxima de elementos informacionais possível para reflexão (segmentos de texto), que servirá para análise sistemática do conteúdo (COUTINHO, 2011).

Questão 1 e 2. A verificação das questões de investigação 1 e 2 foi analisada através das 4 categorias de análise (Cat.) das entrevistas realizadas:

Cat.1: "Percepção da morte em geral face às vivências anteriores dos idosos". Produziu-se várias conceções que dependeram do perfil de cada idoso e da realidade em que se encontravam inseridos (HENNEZEL, 2005). Surgiram 9 subcategorias: aceitação; suscitação do medo; fim do sofrimento; término da vida; processo natural; religiosidade, recompensa/continuidade; negação; perda; sofrimento. As narrativas entrelaçaram diferentes tempos e espaços.

0 conceito de morte atribuído associou-se aos aspetos naturais da vida e da velhice, numa atitude de aceitação, embora alguns idosos refiram que não é bem-vinda e que não estão preparados para morrer, devido ao medo e sofrimento, a doença e abandono da família. A percepção da morte também se associa ao fim do sofrimento do outro, que é 0 término da vida (finitude da vida). A religiosidade foi referenciada como a morte sendo uma recompensa e continuidade da vida. Esta visão de recompensa após a morte associa-se ao pecado original, ao pecado pessoal, à culpa, à esperança, à fé, à ressurreição na carne, e à salvação.

Quanto aos aspetos negativos na concepção da morte destacamos a negação, que leva os idosos a não pensarem nela ou que seja repudiada. Contudo, sua proximidade os 
leva a pensar nela involuntariamente e que se sofra em silêncio (HOWARTH, 2007), sendo considerada uma perda na luta pela vida e um momento de sofrimento pessoal.

Cat.2: "A morte para mim é ...". Foi evidente uma associação livre de palavras pelos idosos, pois verificámos uma porcentagem de termos negativos referenciados $(62,9 \%)$, seguido dos positivos (34,3\%) e dos neutros (2,9\%). Os negativos revelam uma presença de sentimentos fortemente negativos sobre a concepção de morte (morte é o fim, o final de tudo, o fim do ser). Neste sentido, o fim é o rompimento com a vida, o termo da sua jornada, mas com alguma aceitação pelo fato de referirem que é natural, por ser inevitável (KELEM AN, 1997).

Os termos de compreensão positiva estão associados a sua aceitação da morte pelo idoso como um fato Natural/Necessário à renovação, assim como um alívio para a doença, um fim para o sofrimento e etc. implica a visão de que a morte é um reconforto para quem sofre e se encontra dependente. Outro aspeto é a religiosidade com referências ao "Princípio da vida eterna/uma morte santa/Eterno descanso", com forte conotação de uma crença da vida para além da morte e de recompensa pelo que passou durante sua vida (KÓVACS, 2010). Os termos neutros foram referenciados como ausência da vida pois ao morrer tudo acaba, numa demonstração de conformismo perante a morte.

Cat.3: "Percepção da 'morte do outro' a nível institucional". Foram evidenciados aspetos negativos da perda, distintos de idoso para idoso, devido aos fatores intrínsecos à sua adaptabilidade e aos seus modos de enfrentar situações de estresse, bem como ao nível de vínculo estabelecido com o outro. Como subcategorias surgiram a Tristeza/dor/saudade, Aceitação com naturalidade, Indiferença, Aceitação quando há sofrimento e/ou idade avançada e Reflexões de vida.

A referência à emoções fortemente negativas mediante a perda do outro através dos termos tristeza, dor e saudade, que são narrando mesmo quando não existe qualquer tipo de vínculo (M OODY; ARCANGEL, 2006). A indiferença sugere que às perdas anteriores foram as mais importantes, dando a entender que a vivência na instituição não os afetam. $A$ aceitação quando há sofrimento e/ou idade avançada sugere que se sente um alívio quando o outro estava a sofrer e que seja mais bem aceita do que em etapas de vida mais novas (OLIVEIRA, 2008). 
Por fim quando a morte do outro faz com que pense que a sua está próxima, influi na sua percepção de morte e finitude, o que pode desencadear sentimentos negativos e levar muitas vezes à ansiedade.

Cat.4: "Como vivencio a perda de algum colega de instituição". A relação da percepção da morte à frase deu uma maior porcentagem de termos negativos $(62,9 \%)$, seguidos dos neutros $(31,4 \%)$ e positivos $(5,7 \%)$, revelando a presença de sentimentos fortemente negativos na perda do outro, implicando palavras e expressões como: triste/tristeza $(25,7 \%)$, pena $(11,4 \%)$, um bocado chocado $(5,7 \%)$.

Há uma interligação da percepção da 'morte' e da 'morte do outro', em que as narrações emocionais dependeram das caraterísticas pessoais, ambientais e do apoio à que o idoso esteve e está sujeito. Durante o período de institucionalização a morte do outro é promotora de sofrimento em grande parte da amostra, que não acompanhados podem levar a problemas futuros (SOARES et al., 2009). O que torna importante a detecção destes sentimentos negativos e a promoção do apoio após a perda, a fim de minimizarmos os seus efeitos (NEIM EYER, 1997).

Questão 3. Esta questão de investigação foi verificada pela análise das variáveis sociodemográficas relacionadas ao significado das questões nas Escalas: 'morte é' e "morte do outro". Em relação à "morte é" analisamos o seguinte:

- $\quad 0$ gênero apresenta uma variação semelhante tanto em termos negativos com $45,5 \%$ e $54,5 \%$ comparativamente, bem como para os termos positivos com $41,7 \%$ e $58,3 \%$ respectivamente, sendo que nestes ambos os gêneros parecem, em parte, em paz com a ideia da morte ser algo natural, um alívio ao sofrimento e incluem o aspecto religioso como confortador. No sexo masculino pode depreender que a morte é mais aceita, interiorizada, não pensada.

- A prevalência de termos negativos se dá dos $81-90$ anos (40\%), seguido dos 76-80 anos (11,4\%) e dos $91-95$ anos (8,6\%). De igual porcentagem verificamos que os termos positivos concentraram-se na faixa etária dos 86-90 anos (20\%), seguido dos 81-85 anos (5,7\%) e 91-95 anos. 0 avançar da idade em conjunto com as vivências são promotores de uma visão negativa da morte, entretanto observa-se que os idosos vêm a morte como natural e necessária. 
- Quanto a religião, predominantemente católica, averigua-se que a morte é vista como algo negativo, com $61,8 \%$ da amostra referindo ser o fim de tudo, uma tristeza. $E$ 0 único ateu referiu-se negativamente também. Quanto aos termos positivos, observamos 35,3\% dos católicos a aceitá-la de forma natural e necessária.

- $\quad 0$ estado civil indica-nos quanto aos termos negativos uma maior prevalência dos viúvos (51,4\%), seguido dos solteiros (8,6\%) e divorciados (2,9\%). Dos termos positivos houve maior prevalência também nos viúvos $(25,7 \%)$, seguidos dos casados $(5,7 \%)$ e dos solteiros (2,9\%). 0 que nos leva a depreender que o estado de viuvez leva à percepção negativa da morte, como fim, uma coisa triste, má e escura. Embora também tenham sido os viúvos com maior prevalência dos termos positivos.

Enquanto a análise da 'morte do outro' obtivemos:

- $\quad$ No gênero do sexo feminino, 85\% referem termos negativos, 31,4\% termos neutros; no sexo masculino 53,3\% referem termos neutros e 5,7\% de termos positivos. Observa-se assim que o sexo masculino exibiu uma maior frequência nas compreensões neutras e positivas, numa atitude mais conformista frente às perdas;

- Maior prevalência de termos negativos (62,9\%), conforme a idade, correspondem à: $80 \%$ na faixa etária dos $81-85$ e 57,1\% na faixa etária dos $86-90$. Houve $31,4 \%$ que referiram termos neutros - 42,9\% na faixa etária dos 86-90. Assim, o aumento da idade propícia o encarar a perda do outro de forma mais negativa.

- A religião católica apresenta $62,9 \%$ de referências negativas e $31,4 \%$ de neutras na questão. A perda do outro durante a institucionalização é um momento de sofrimento/dor, não sendo uma condicionante favorecedora de sentimentos negativos.

- $\quad 0$ estado civil indica-nos termos negativos nos viúvos $(71,4 \%)$ e solteiros (50\%) e termos neutros em $28,6 \%$ viúvos. Os positivos foram referenciados por um idoso solteiro e um idoso divorciado. Considera-se, assim que a viuvez é uma condicionante que favorece a sentimentos/ expressões negativas na vivência da perda do outro.

Por conseguinte, as variáveis sociodemográficas influenciam os significados das representações dos idosos institucionalizados quanto à morte e à morte do outro (SILVA, 2006). O sexo masculino aceita de forma mais interiorizada a morte exibindo uma atitude conformista frente às perdas, sabendo que na velhice se promove pensamentos negativos (SOARES et al., 2009). 
A religião católica promove uma aceitação da morte como facto natural não sendo um condicionante de sentimentos negativos após a perda; a viuvez leva à percepção da 'morte' e 'morte do outro' de forma negativa.

Questão 4. Valores de correlação entre às variáveis sociodemográficas, ou seja, a relação das representações da 'morte' e 'morte do outro'. Verificou-se (Quadro 1):

- Os valores observados na correlação entre às variáveis sociodemográficas e a morte demonstrou moderada correlação negativa entre religião e idade $(r=, 550 ; p<01)$ e as habilitações literárias e 0 estado civil $(r=, 474 ; p<01)$. Valores idênticos encontraram-se na relação entre a 'perda do outro', embora de nível de significância $p \geq 0,05$, em que a correlação entre as variáveis sociodemográficas indicam predisposição negativa na percepção da morte, como a idade avançada e a viuvez.

Há uma correlação moderada negativa entre 0 estado civil e a religião $(r=, 421 ; p$ $<05)$, que nos leva a inferir que a percepção da morte sofre uma influência negativa da religiosidade para o idoso, numa amostra maioritariamente católica.

- Os valores observados na correlação entre às variáveis sociodemográficas e 'perda do outro', deram uma correlação moderada positiva entre a perda do outro e a idade $(r=349 ; p<01)$, que nos leva a inferir uma forte influência da religiosidade para o idoso. Há uma forte correlação negativa entre religião e idade $(r=, 550 ; p<05)$, habilitações literárias e estado civil $(r=, 474 ; p<05)$ e a perda do outro e o género $(r=, 443 ; p<05)$. Quanto às variáveis sociodemográficas há moderada correlação negativa entre a religião e a idade implicando que a idade avançada é um fator de predisposição na perda; para além das habilitações literárias e estado civil, isto é, baixa iletrância e a viuvez; 0 gênero maioritariamente feminino correlaciona-se com a 'perda do outro'.

Questão 5. As Escalas Breves Sobre Diversas Perspectivas da Morte apresentaram uma boa consistência geral de alfa de Cronbach $=0,826$, assim como entre às 8 subescalas exceto MI, MD e MF (Quadro 1). 
Quadro 1 - Cronbach Alfa das Escalas Breves So bre Diversas

Perspectivas da M orte

\begin{tabular}{|c|c|c|c|}
\hline & Alfa de Cronbach & $\begin{array}{l}\text { Alfa de Cronbach } \\
\text { Baseado nos Itens } \\
\text { Estandardizados }\end{array}$ & $\mathrm{N}$ de Itens \\
\hline SS & ,618 & 627 & 6 \\
\hline VA & 810 & 822 & 6 \\
\hline $\mathrm{MI}$ &, 520 &, 527 & 5 \\
\hline MD & ,618 &, 638 & 6 \\
\hline MA & ,743 & ,739 & 5 \\
\hline MC & ,766 & ,766 & 6 \\
\hline $\mathrm{MF}$ & ,640 & 617 & 5 \\
\hline MN & ,777 & ,774 & 4 \\
\hline
\end{tabular}

Nota: SS = Sofrimento e Solidão; $V A=$ Vida Além Recompensa; MI = Morte com Indiferença; $\mathrm{MD}=$ Algo Desconhecido; $\mathrm{MA}=\mathrm{Abandono}$ dos que dependem de nós com culpabilidade; $\mathrm{MC}=$ Morte como Coragem; $\mathrm{MF}=$ Morte como Fracasso; $\mathrm{MN}=$ M orte como Algo Natural.

Fonte: 0 autor

Em termos gerais as escalas e subescalas se correlacionam da seguinte maneira: forte e descrescente entre MF e MC ( $r=604 ; p<01)$, a MA $(r=590 ; p<01)$, a MD ( $r=548 ; p$ $<01)$; a subescala MC com uma forte correlação com VA ( $r=458 ; p<01)$ e moderada com MD ( $r=425 ; p<05), M A(r=, 406 ; p<05)$; a subescala M A com uma forte correlação com M D $(r=460 ; p<01)$ e moderada com SS $(r=354 ; p<05)$.

Podemos deduzir que o significado atribuído pelos idosos à morte depende da percepção da sua vida atual, sendo vista no ambiente institucional como um último teste da vida, embora a encarem como 'abandono de quem amam' ou 'desconhecido', além de levar aos sentimentos de sofrimento/dor, agonia e isolamento.

No Quadro 2 estabelecemos as correlações entre os resultados das oito subescalas e às variáveis sociodemográficas: 
Quadro 2 - Correlações entre as oito subescalas de Escalas Breves Sobre Diversas Perspectivas da Morte e variáveis sociodemográficas

\begin{tabular}{|c|c|c|c|c|c|c|c|c|c|c|c|c|c|}
\hline & SS & $\overline{V A}$ & $\mathrm{MI}$ & $\overline{M D}$ & $\overline{M A}$ & $\overline{M C}$ & $\overline{M F}$ & $\mathrm{MN}$ & Género & Idade & Religião & $\begin{array}{c}\begin{array}{c}\text { Estado } \\
\text { civil }\end{array} \\
\end{array}$ & $\begin{array}{l}\text { Habilitações } \\
\text { literárias }\end{array}$ \\
\hline SS & 1 & & & & & & & & & & & & \\
\hline VA & ,292 & 1 & & & & & & & & & & & \\
\hline$\overline{\mathrm{MI}}$ &,- 176 & ,052 & 1 & & & & & & & & & & \\
\hline$\overline{M D}$ & ,284 & ,125 &,$- 391^{*}$ & 1 & & & & & & & & & \\
\hline$\overline{\mathrm{MA}}$ &, $354^{*}$ &,- 157 &,- 176 &, $460^{* *}$ & 1 & & & & & & & & \\
\hline$M C$ & ,398* &, $458^{* *}$ &,- 033 & $425^{*}$ & $406^{*}$ & 1 & & & & & & & \\
\hline$\overline{\mathrm{MF}}$ & $351^{*}$ & ,088 &,$- 482^{* *}$ &, $548^{* *}$ &, $590^{* *}$ &, $604^{* *}$ & 1 & & & & & & \\
\hline$\overline{M N}$ &,- 012 &,- 013 & 094 & ,235 & ,295 & , 177 & , 194 & 1 & & & & & \\
\hline Género & , 179 &,- 017 &,- 306 &, $459^{* *}$ & ,146 &,- 007 & ,148 & 100 & 1 & & & & \\
\hline Idade & 153 & ,372* &,- 070 &, 276 &,- 013 & ,155 & ,181 & ,151 & 099 & 1 & & & \\
\hline Religião &,- 206 &,$- 357^{*}$ & 230 &,$- 480^{* *}$ &,- 047 &,$- 349^{*}$ &,- 091 &,- 241 &,- 198 &,$- 550^{* *}$ & 1 & & \\
\hline Estado civil & 083 &,- 060 &,- 200 & ,307 &, 006 & ,087 &,- 011 &,- 104 & 209 &, 253 &,$- 421^{*}$ & 1 & \\
\hline $\begin{array}{l}\text { Habilitaçōes } \\
\text { literárias }\end{array}$ &,- 296 & 216 &,- 061 & ,015 &,- 242 & -101 & 027 &,- 049 & ,028 & -189 & ,229 &,$- 474^{* *}$ & 1 \\
\hline
\end{tabular}

Nota: SS = Sofrimento e Solidão; VA=Vida Além Recompensa; MI = M orte com Indiferença; MD =Algo

Desconhecido; $\mathrm{MA}=$ Abandono dos que dependem de nós com culpabilidade; $\mathrm{MC}=\mathrm{M}$ orte como

Coragem; M F = Morte como Fracasso; $\mathrm{MN}=$ Morte como Algo Natural.

* Correlação significativa para nível 0.05;

** Correlação significativa para nível 0.01

Fonte: 0 autor

Os dados levam-nos a inferir que o gênero influi na percepção da morte como algo que não se conhece e negativamente com a sua indiferença, evidenciada no sexo masculino. A idade indica que os idosos em idade avançada acreditam que existe vida além da morte. Quanto à religião, pode-se inferir pelos dados que não apresenta grande representatividade na minimização do sofrimento perante à morte.

Os de estado civil viúvo apresentam medo da morte como algo desconhecido, encarando-a com alguma coragem, embora com receio do sofrimento que poderá advir no processo e abandono dos que ama. As habilitações literárias apresentam baixas correlações com acreditar na vida além morte e como recompensa, como sendo um fracasso na luta pela vida e medo do desconhecido.

Entre a Escala Breve Sobre Diversas Perspectivas da Morte e a Escala Geriátrica de Depressão (GDS-30), observa-se (Quadro 3) uma correlação moderada e positiva com Sofrimento e Solidão ( $r=353 ; p<05)$, o que sugere uma relação direta entre o sofrimento, abandono de quem se ama e a culpa perante a morte como promotor de sinais depressivos. Indicadores de que os sinais depressivos apresentados podem estar relacionados com a percepção da morte, dentre outros. 
Quadro 3 - Correlações entre as oito subescalas de Escalas Breves Sobre Diversas Perspectivas da Morte e a GDS-30

\begin{tabular}{c|r|r|r|r|r|r|r|r|r}
\hline & \multicolumn{1}{|c|}{ SS } & \multicolumn{1}{c|}{ VA } & \multicolumn{1}{c|}{ MI } & \multicolumn{1}{c|}{ MD } & \multicolumn{1}{c|}{ MA } & \multicolumn{1}{c}{ MC } & MF & MN & GDS-30 \\
\hline SS & 1 & & & & & & & & \\
\hline VA &, 292 & 1 & & & & & & & \\
\hline MI &,- 176 &, 052 & 1 & & & & & & \\
\hline MD &, 284 &, 125 &,$- 391^{*}$ & 1 & & & & & \\
\hline MA &, $354^{*}$ &,- 157 &,- 176 &, $460^{* *}$ & 1 & & & & \\
\hline MC &, $398^{*}$ &, $458^{* *}$ &,- 033 &, $425^{*}$ &, $406^{*}$ & 1 & & & \\
\hline MF &, $351^{*}$ &, 088 &,$- 482^{* *}$ &, $548^{* *}$ &, $590^{* *}$ &, $604^{* *}$ & 1 & & \\
\hline MN &,- 012 &,- 013 &, 094 &, 235 &, 295 &, 177 &, 194 & & 1 \\
\hline GDS-30 &, $353^{*}$ &,- 234 &,- 120 &, 152 &, 006 &,- 197 &, 001 &,- 238 & \\
\hline
\end{tabular}

Nota: SS = Sofrimento e Solidão; VA=Vida Além Recompensa; MI = Morte com Indiferença; MD =Algo Desconhecido; $M A=A$ bandono dos que dependem de nós com culpabilidade; $M C=$ Morte como Coragem; $\mathrm{MF}=\mathrm{M}$ orte como Fracasso; $\mathrm{MN}=\mathrm{M}$ orte como Algo Natural.

* Correlação significativa para nível 0.05

** Correlação significativa para nível 0.01

Fonte: 0 autor

\section{Questão 6 (entrevistas e notas de campo)}

Os apoios fornecidos nas 2 instituições, de acordo com a concepção dos idosos após a perda do outro, levou-nos a estabelecer três subcategorias: Atributo positivo, com subcategoria II de Adequado; Atributo negativo, com subcategorias II de Ocultação, Ausente e Insuficiente e Atributo neutro, com subcategorias II de Indiferença e Alienação.

O Atributo positivo indica uma boa percepção do apoio fornecido pelas instituições (Satisfação), relatando os idosos que é Adequado. Embora sejam acompanhados há relatos que não consideram minimizado o sofrimento da perda. Através do Atributo negativo observamos a Ocultação, em que o idoso é afastado da morte do outro, e o apoio Ausente e por vezes Insuficiente. Quanto ao Atributo neutro, verifica-se um afastamento por parte do idoso nos momentos da morte do outro, observando-se demonstrações de indiferença e de alienação.

Apesar de considerarem que o apoio é satisfatório, torna-se necessário observar e acompanhar os idosos que o consideram Ausente e Insuficiente e trabalhar na questão da Ocultação. Sendo assim, existe necessidade por parte dos profissionais conhecerem 0 processo de morte e do morrer, para assim promoverem um adequado cuidado/acompanhamento.

De fato os idosos sentem a necessidade de terem um tipo de apoio após a perda do outro. Na análise desta necessidade verificámos que o apoio fornecido após a perda a nível 
institucional depende das caraterísticas da instituição. Nessas respostas evidenciámos cinco subcategorias: Satisfatório, Necessário, Indiferente, Não necessário e o Apoio fornecido. Nesta última registámos expressões como: "não podem mais", "não conseguem" e "não querem saber".

O apoio considera-se "Satisfatório" quando é considerado adequado e suficiente, não havendo referencias à necessidade de melhorias e/ou alterações; o apoio é "Necessário" quando sentem necessidade de o receberem, sem referências ao que necessitam; é "Indiferente" quando consideram a morte como algo inalterável, como um dado certo e adquirido durante o processo de institucionalização, quando não pensam nessa necessidade e quando não se evidencia a criação de laços com o outro. Ou seja, há um afastamento da realidade envolvente, o que porventura não é promotor de grande sofrimento (M ORIN, 1970). Quanto ao apoio "Não necessário" os idosos sentem-se capazes de superar a perda, fazendo uso das suas próprias capacidades de enfrentamento.

Em relação ao apoio após as perdas a maioria dos idosos o consideram "Satisfatório". 0 apoio fornecido é avaliado pelo idoso mediante suas vivências de morte na instituição, considerando a "Intervenção limitada", "Falta de preparo" e "Indiferença", nos levando a reiterar a necessidade de preparação e formação profissional, avaliando suas próprias capacidades de lidar e apoiar o próximo num momento complexo como é o da morte (REBELO, 2004).

Os profissionais dos lares residenciais vivem os processos de luto pela perda do outro de duas formas: 0 seu próprio processo, que muitas das vezes não é autorizado e compreendido; e o processo do idoso sob o seu cuidado.

\section{Reflexões finais}

Em termos gerais os resultados da pesquisa permitiram verificar que as perspectivas da "morte" e da "morte do outro" estão relacionadas com o sentido de vida do idoso, o ambiente institucional e suas percepções (GIACOIA JUNIOR, 2005). Portanto, suas concepção de "morte" é vista como um último teste a vida, o abandono de quem se ama e algo "desconhecido", além de ser um momento de sofrimento, dor, agonia e isolamento (DÉM UTHOVÁ, 2012). A percepção da "morte do outro" associa seus conceitos de morte e 
finitude, implicando o desencadeamento de sentimentos negativos e estados de ansiedade (DRAGO; M ARTINS, 2012).

Quanto às perdas sofridas na sua rede de relações sociais e familiares antes da institucionalização, os idosos atribuíram maior importância aos familiares diretos, verificando-se a influência do choro, tristeza e mágoa que frequentemente apresentavam nas suas narrativas. Neste contexto, o 'fim' é o rompimento com a vida (desprendimento), com alguma aceitação (resignação) pelo fato de ser natural e um acontecimento inevitável. Evidenciamos a negação, repudio ou afastamento da ideia, entretanto sua proximidade no ciclo de vida leva a que se pense nela involuntariamente e que se transmita uma sensação de dor em silêncio. A morte é considerada como uma perda na luta pela vida e um momento de sofrimento pessoal (DAVIES, 2005; THOMAS, 1991).

$\mathrm{Na}$ percepção da 'morte do outro' a nível institucional evidenciamos aspectos negativos da perda, diferindo de idoso para idoso devido a fatores intrínsecos, adaptabilidade e sua forma de enfrentar de situações de estresse, bem como do vínculo estabelecido com o outro. A morte deste faz com que se pense que a sua 'está próxima' e então influir à percepção da morte como finitude, desencadeando sentimentos negativos que levam a ansiedade e situações de depressão ou tristeza (DJIRE et al., 2012). As várias manifestações de depressão no idoso e a dificuldade do seu diagnóstico diferencial, entre outros fatores, determinam estados depressivos (FERNANDES, 2010; VARA, 2012).

Os idosos percecionam que o apoio dos profissionais é satisfatório, mas ainda há alguns que os consideram 'Ausentes' e 'Insuficientes'. Esse apoio prestado não minimiza o sofrimento da perda, sendo necessário que esses profissionais e voluntários conheçam o processo de morte e do morrer nessa idade, para assim promoverem um cuidado e trato adequado - diferente de instituição para instituição, observando-se uma "Ocultação" no intuito de proteger os idosos. 0 cuidado ao idoso centra-se em suas necessidades, no respeito pela sua individualidade e minimização do sofrimento/dor.

Os profissionais dos lares necessitam de competências para lidar com essas perdas e ligação com o idoso, sendo uma questão de difícil de abordar (KNOCH, 2003). Contudo, o profissional da saúde não só deve acompanhar o idoso, mas também aprender a lidar com seus próprios sentimentos e saber cuidar e cuidar-se, estabelecendo um bom alicerce pela relação de ajuda (CARVALHO; DIAS, 2011). 
Na perda do outro, os profissionais de saúde confrontam-se sistematicamente com o sofrimento, que pode levar à um desgaste na relação estabelecida entre estes e 0 idoso (AGOSTINHO, 2004). Será necessário desenvolver ações orientadas a manutenção da qualidade de vida no seu cotidiano, aproximando os conhecimentos e construindo suas práticas no dia-a-dia.

\section{Referências}

AGOSTINHO, P. Perspectiva psicossomática do envelhecimento. Revista Portuguesa de Psicossomática, Lisboa, v. 6, n. 1, p. 31-36, jan./jun., 2004.

BARBOSA, A. Pensar a morte nos cuidados de saúde. Análise Social, Lisboa, v. XXXVIII, n. 166, p. 35-49, 2003.

BARDIN, L. Análise de conteúdo. 4. ed. Lisboa: Edições 70, 2009.

BARROS-OLIVEIRA, J.; NETO, F. Validação de um instrumento sobre diversas perspectivas da morte. Análise Psicológica, Lisboa, v. 2, n. 22, p. 355-367, 2004.

BENGSTON, V. et al. (ed.). Handbook os theories of aging. New York: Springer, 2009.

BOGDAN, R.; BIKLEN, S. Investigação qualitativa em educação: uma introdução à teoria e aos métodos. Porto: Porto Editora, 1994.

CABRAL, M . et al. Processo de envelhecimento em Portugal. Lisboa: Fundação Francisco Manuel dos Santos, 2013.

CARDÃO, S. 0 idoso institucionalizado. Lisboa: Coisas de Ler, 2009.

CARVALHO, M. P. R. S.; DIAS, M. O. Adaptação dos idosos institucionalizados. M illenium, Viseu, n. 40, p. 161-184, 2011.

CLAVANDIER, G. Sociologie de la mort. Paris: Armand Colin, 2009

COUTINHO, C. M etodologia de investigação em ciências sociais e humana: teo ria e prática. Coimbra: Almedina, 2011.

DAVIES, D. J. História da morte. Lisboa: Editorial Teorema, 2005.

DÉM UTHOVÁ, S. The most frequent connotations of the concept of death in young adults. Ostium: Revista Online para Humanidades, v. 8, n. 2, p. 1-11, 2012.

DJIRE, S. et al. Five residents speak: the meaning of living with dying in a long-term care home. Death Studies, Washington, v. 36, n. 6, p. 487-518, 2012.

DRAGO, S.; M ARTINS, R. A depressão no idoso. Millenium, Viseu, n. 43, p. 79-94, jun/dez. 2012. 
FERNANDES, S. Vivências em lares de idosos: diversidade de percursos, um estudo de caso. 2010. 155f. Dissertação (M estrado em Gerontologia Social) - Universidade Portucalense, Porto, 2010.

FLICK, U. M étodoss qualitativos na investigação científica. Lisboa: M onitor, 2005.

FORTIN, M . O processo de investigação: da concepção à realização. Loures: Lusociência, 1999

FRUMI, C.; CELICH, K. O olhar do idoso frente ao envelhecimento e à morte. Revista Brasileira de Ciências do Envelhecimento Humano, Passo Fundo, v. 3, n. 2, p. 92-100, jul./dez. 2006.

GALLHA, L. Morte assistida. Alfragide: Oficina do Livro, 2013.

GIACOIA JUNIOR, O. A visão da morte ao longo do tempo. M edicina, Ribeirão Preto, v. 38, n. 1, p. 13-19, 2005.

GUERRA, A.; CALDAS, C. Dificuldades e recompensas no processo de envelhecimento: a percepção do sujeito idoso. Ciência \& Saúde Coletiva, Rio de Janeiro, v. 15, n. 6, p. 29312940,2010

HENNEZEL, M. Diálogo com a morte. Cruz Quebrada: Casa das Letras, 2005.

HOWARTH, G. Death and dying: a sociological introduction. Cambridge: Polity Press, 2007.

INSTITUTO DE SEGURANÇA SOCIAL - ISS. M anual de boas práticas: um guia para o acolhimento residencial das pessoas em situação de deficiência para dirigentes, profisssionais, residentes e familiares. Lisboa: Instituto de Segurança Social, 2005.

KELEM AN, S. Viver o seu morrer. São Paulo: Summus, 1997.

$\mathrm{KNOCH}$, Michel. A deontologia dos assistentes sociais como ética profissional. Intervenção Social, Lisboa, n. 27, p. 5-30, 2003.

KÓVACS, M. M orte e desenvolvimento humano. São Paulo: Casa do Psicólogo, 2010.

KÜBLER-ROSS, E. Sobre a morte e o morrer. São Paulo: M artins Fontes, 2005.

LIM A, C.; M URAI, H. Percepção do idoso sobre o próprio processo de envelhecimento. Revista de Enfermagem UNISA, São Paulo, n. 6, 261-270, 2005.

M ARTINS, E. C. Gerontologia \& Gerontagogia: a animação sociocultural em idosos. Lisboa: Cáritas Editora, 2013.

M OODY, R.; ARCANGEL, D. Vida depois da perda: como ultrapassar a dor e encontrar a esperança. Cascais/Lisboa: Pergaminho, 2006.

M ORAGAS, R. Gerontologia social: envelhecimento e qualidade de vida. São Paulo: Edições Paulinas, 1997.

M ORIN, E. L'homme et la mort. Paris: Éditions du Seuil, 1970. 
NEIM EYER, R. A. M étodos de evaluación de la ansiedad ante la muerte. Barcelona: Paidós, 1997.

NETTO, M. Gerontologia: a velhice e o envelhecimento em visão globalizada. São Paulo: Atheneu, 2002.

OLIVEIRA, A. O desafio da vida. Lisboa: Coisas de Ler, 2011.

OLIVEIRA, A. O desafio da morte. 2. ed. Lisboa: Âncora Editora, 2008.

PUIGDENGOLAS, F. Acompanhar pessoas idosas em lares. São Paulo: Ed. Paulinas, 2003.

SILVA, J. Quando a vida chegar ao fim. Loures: Lusociência, 2006.

SOARES, J. et al. 0 idoso institucionalizado e a reflexão sobre a própria morte. Revista Kairós: gerontologia, São Paulo, v. 12, n. 1, p. 135-147, jan. 2009.

REBELO, J. Desatar o nó do luto. Lisboa: Casa das Letras, 2004.

THOM AS, L. V. La muerte. Barcelona: Paidós, 1991.

VARA, M. O olhar do gerontólogo. In: F. PEREIRA, (coord.). Teoria e prática da gerontologia: um guia para cuidadores idosos. Viseu: PsicoSoma, 2012. p. 65-77.

VERÍSSIM O, M. T. Avaliação diagnóstica dos síndromes demenciais: escala da depressão geriátrica. Porto: Universidade do Porto, 1988.

YESAVAGE, J. A. et al. Development and validation of a geriatric depression screening scale. Journal of Psychiatric Research, Oxfort, v. 17, n. 1, p. 37-49, 1983. 